\title{
A morphometric study of regional variation in lung structure in infants with pulmonary hypertension and congenital cardiac defect $A$ justification of lung biopsy
}

\author{
SHEILA G. HAWORTH AND LYNNE REID \\ From the Department of Paediatric Cardiology, Hospital for Sick Children, Great Ormond Street, London; \\ and the Department of Pathology, The Children's Hospital Medical Center, 300 Longwood Avenue, Boston, \\ U.S.A.
}

SUMMARY The structure of the pulmonary circulation throughout the lung has been analysed by morphometric techniques in 4 infants dying with ventricular septal defect and pulmonary hypertension. Failure of the intra-acinar pulmonary circulation to develop normally is shown by a reduction in arterial size and number, and an increase in muscularity is judged by the degree of medial hypertrophy and by extension of muscle further along the arterial pathway than is normal. For these features, one section of lung tissue, $1 \mathrm{~cm}$ square, proved to be representative of the entire pulmonary vascular bed, and also gave satisfactory assessment of lung growth and development. Lung biopsy can help in the clinical management of children with corigenital cardiac defects and pulmonary hypertension if, in selecting tissue at biopsy, allowance is made for any regional differences in pulmonary blood flow.

Examination of lung tissue obtained at biopsy has come to be regarded as of limited value in the management of children with pulmonary hypertension complicating congenital heart disease, mainly because it is thought that the findings in such a small piece of lung are not representative of the whole (Wagenvoort et al., 1964).

If the pulmonary circulation is distended before examination the vessel size, number, and wall thickness can be reliably established. In the normal lung of both adult (Simons and Reid, 1969) and child (Hislop, 1971) no regional differences in vessel structure have been found, though the lingula may be an exception since abnormally thick walled arteries have been reported by Heath and Best (1958) but not by Wagenvoort (1960). In the injected pulmonary arterial circulation of the lungs of children and adults dying with atrial or ventricular defects or a persistent ductus arteriosus, neither Harrison (1958) nor Wagenvoort (1960) found any regional difference in arterial medial thickness.

In certain diseases regional differences are found.

Received for publication 7 November 1977
In mitral stenosis associated with pulmonary hypertension medial hypertrophy is more severe in lower than in upper lobe arteries, both in the injected postmortem specimen (Harrison, 1958) and in biopsy tissue (Heath and Best, 1958). Irrespective of the cause of pulmonary hypertension the vascular lesions associated with more advanced pulmonary vascular disease may vary in severity even within a small volume of lung tissue (Wagenvoort et al., 1964; Hoffman, 1972).

In a recent study using quantitative morphometric techniques on the injected lung, we have analysed the structural changes in the pulmonary circulation of young children dying with a ventricular septal defect and pulmonary hypertension and we have shown a failure of arterial growth, the development of medial hypertrophy, and abnormal extension of muscle associated with pulmonary hypertension (Haworth et al., 1977). None of these children had developed the later stages of obliterative pulmonary vascular disease. In such patients information about the state of lung growth and the onset of obliterative pulmonary vascular disease is important in deciding when to plan surgical treatment and whether this should be palliative or corrective. To establish 
whether the changes are sufficiently uniform to justify biopsy and, if so, whether the amount of tissue obtained at biopsy is sufficient to assess the state of alveolar and vessel growth and the presence and severity of pulmonary vascular disease, we have examined in detail tissue from various lung sites taken from 4 of the patients from the published series (Haworth et al., 1977).

\section{Subjects and methods}

\section{CLINICAL FEATURES}

Four infants between 5 and 10 months old were studied, 2 with a ventricular septal defect and 2 with an atrioventricular canal. They are described in order of increasing age (Table). All presented in cardiac failure, had a hyperactive cardiac impulse, a pansystolic murmur of maximal intensity at the lower left sternal edge, and accentuation of the pulmonary component of the second heart sound. In all cases the chest radiograph showed cardiac enlargement, the cardiothoracic ratio exceeding 60 per cent. Hilar and proximal pulmonary arteries were dilated, in contrast to the mid lung vessels which were not. The electrocardiogram showed signs of right ventricular hypertrophy and the mean frontal plane QRS axis was further to the right than is normal in cases 2 and 4 and superior in cases 1 and 3, the two with an atrioventricular canal. Cardiac catheterisation disclosed a pulmonary arterial pressure at systemic level in all but one child (case 2) in whom it was higher than two-thirds of the systemic arterial pressure.

\section{METHODS}

In cases 1 and 2 both pulmonary arteries were injected with a barium sulphate/gelatin suspension; in case 3 the right pulmonary artery and in case 4 the left was injected, the pulmonary veins being injected in the other lung. The barium sulphate/ gelatin suspension was injected at a temperature of $60^{\circ} \mathrm{C}$ and at a pressure of $100 \mathrm{~cm}$ water. The lungs were then inflated through the trachea with a buffered formol-saline solution at a pressure of $45 \mathrm{~cm}$ water and allowed to fix. Each lung was then radiographed and sliced (Davies and Reid, 1970; Hislop and Reid, 1970) and blocks of tissue $1 \mathrm{~cm}^{2}$ were taken from certain regions of each lobe in order to compare the structure in different parts of the same lobe, in different lobes of the same lung, and, in 2 cases, in both lungs.

Four blocks were taken from each of the upper and lower lobes (save in case 2 where from the left lower lobe only 2 blocks were taken, injection in the rest of the lobe being unsatisfactory). One block was taken from each of the following 4 sites, anterior, posterior, central, and subpleural regions. In cases 1 and 4 an additional block was taken from the lingula. Since not all the tissue was suitable for analysis of all the structural features the number of sections analysed statistically was sometimes less than the number of blocks taken. In particular, consolidation and collapse make tissue unsuitable for counting arteries and alveoli per unit area. To assess pulmonary arterial muscularity the percentage arterial medial thickness and the level to which muscle extended along the arterial pathway was determined. Vascular growth was assessed by the size and number of peripheral arteries.

\section{Percentage arterial medial thickness}

The external diameter of an artery was measured across two diameters by taking the distance between external elastic laminae; wall thickness was measured from external to internal elastic lamina at the 4 sites where the measured diameters cut the wall and the mean of the 4 readings was used. The percentage medial wall thickness was then calculated as:

$$
\frac{2 \times \text { wall thickness }}{\text { external diameter }} \times 100
$$

For each section arteries were grouped in size ranges of 0 to $50 \mu \mathrm{m}, 51$ to 100,101 to 150,151 to 200,201 to 300,301 to 400,401 to 500,501 to 1000 , and over $1000 \mu \mathrm{m}$ and the mean and standard error of percentage wall thickness for each size group were calculated. Percentage medial thickness was determined for an average of 465 arteries in each lung. There were sometimes too few of the larger arteries in a single section to allow comparison between sections within one lobe, but it was possible to make a comparison between the different lobes and lungs in the same case.

\section{Peripheral arterial structure and size}

Size or wall structure of peripheral arteries can be compared if they are identified by reference to the type of accompanying airway. In the present study only those arteries accompanying respiratory bronchioli were compared because, unlike the more proximal airways a sufficient number of respiratory bronchioli can be identified from a single section to allow a statistical analysis of vessel size and structure to be made. Furthermore, unlike more distal airways, respiratory bronchioli and their accompanying arteries can be identified precisely. The external diameter of arteries accompanying this type of airway was measured and the wall structure was determined. At the periphery of any arterial pathway, the muscle coat that entirely surrounds an artery gives way to a spiral of muscle. Such an artery 
Table Case material

\begin{tabular}{llllll}
\hline $\begin{array}{l}\text { Case } \\
\text { no. }\end{array}$ & Diagnosis & $\begin{array}{l}\text { Ageat } \\
\text { death } \\
(\text { mth })\end{array}$ & $Q p / Q s$ & $\begin{array}{l}\text { Rpa } \\
\left(\text { units } m^{2}\right)\end{array}$ & $\begin{array}{l}\text { Lung(s) } \\
\text { analysed }\end{array}$ \\
\hline 1 & $\begin{array}{l}\text { Atrioventricular } \\
\text { canal }\end{array}$ & 5 & 1.36 & 11.2 & $\mathrm{R}, \mathrm{L}$, lingula \\
2 & $\begin{array}{c}\text { Ventricular } \\
\text { septal defect }\end{array}$ & 6 & 2.80 & 3.6 & $\mathrm{R}, \mathrm{L}$ \\
3 & $\begin{array}{c}\text { Atrioventricular } \\
\text { canal }\end{array}$ & 9 & 1.04 & 11.0 & $\mathrm{R}$ \\
4 & $\begin{array}{c}\text { Ventricular } \\
\text { septal defect }\end{array}$ & 10 & 1.50 & 6.5 & L, lingula \\
\hline
\end{tabular}

Qp/Qs, pulmonary/systemic flow ratio; Rpa, pulmonary arteriolar resistance.

cut in cross-section appears as a partially muscular vessel (Reid, 1965). The extension of muscle along an artery can be determined by relating the structure of an artery to its accompanying airway. Thus the muscularity of an artery is assessed in relation to its size and to its position in the arterial pathway.

In each section the wall structure and external diameter of 15 to 20 arteries accompanying respiratory bronchioli were determined. In all 4 cases, in each section, at this level only muscular or partially muscular arteries were found. The percentage of each type was estimated. The percentage of muscular and partially muscular arteries and the mean and standard error of their external diameter were calculated for each lobe and in cases 1 and 2 for each lung. In addition the mean and standard error of external diameter were calculated for each section.

\section{Arterial and alveolar number per unit area: alveolar/ arterial ratio}

In 25 fields from each section the number of arteries of $200 \mu \mathrm{m}$ or less and the number of alveoli were counted and the mean number of arteries and alveoli per field was calculated for each section, each lobe, and in cases 1 and 2 each lung. The alveolar/ arterial ratio was determined for each section and the mean ratio for each lobe and, in cases 1 and 2, the ratio for each lung was calculated.

Using Student's $\mathbf{t}$ test statistical comparisons were made between sections from the same lobe, of the upper and lower lobe of the same lung, in cases 1 and 2 of the right and left lung, and in cases 1 and 4 of the lingula and the rest of the left lung. A P value greater than 0.05 is not considered statistically significant.

\section{Results}

In all these cases the pulmonary arterial circulation was abnormally muscular as shown by an increased wall thickness and extension of muscle abnormally far to the periphery, and the intra-acinar arteries were greatly reduced in size and number. Each section from each patient was clearly abnormal for each feature studied and the analysis is concerned therefore to determine differences as between sections from a given patient in the degree of severity of the various changes.

The findings within one section of lung tissue are presented first. For each structural feature the mean value and range is compared with the normal to discover whether examination of a single section underestimates the severity of overall structural change. The structural features are then compared with the same lobe, the same lung, and, in cases 1 and 2, the two lungs of the same case.

\section{(1) WITHIN ONE SECTION OF LUNG TISSUE Arterial muscularity}

Within any one section of lung tissue the percentage wall thickness of individual pulmonary arteries varied considerably, but in all 42 sections analysed the mean value of arteries of all size groups was above the normal mean level (Fig. 1), except for arteries of 50 to $100 \mu \mathrm{m}$ in diameter in one section from the left upper lobe in case 4. In all sections the smaller the artery the larger the range of values and for arteries less than $300 \mu \mathrm{m}$ in diameter the percentage wall thickness generally showed a range in excess of 3 per cent. Single readings of percentage wall thickness could fall below the normal mean.

In all 4 cases in every section muscle clearly extended further along the arterial pathway than is normal (Hislop and Reid, 1973). In the normal lung, even by 10 months of age 17 per cent of arteries accompanying the respiratory bronchioli still have a non-muscular structure, 72 per cent a partially muscular, and only 11 per cent are entirely muscularised. In these 4 cases no non-muscular arteries were seen. The proportion of entirely muscular and partially muscular arteries varied considerably, but in 32 out of 38 sections at least 68 per cent of arteries were entirely surrounded by a muscle coat.

\section{Size of arteries accompanying respiratory bronchioli}

In all 4 cases in each section the mean external diameter of arteries accompanying the respiratory bronchioli was abnormally small; it was similar to that seen in the normal lung at birth, though individual values varied considerably, the largest vessels falling within the normal range (Fig. 2). The deviation from normal increased with age, until by 9 months (case 3) the greatest mean value found in any section was $99.5 \mu \mathrm{m}$, far below the normal mean of $184 \mu \mathrm{m}$. 


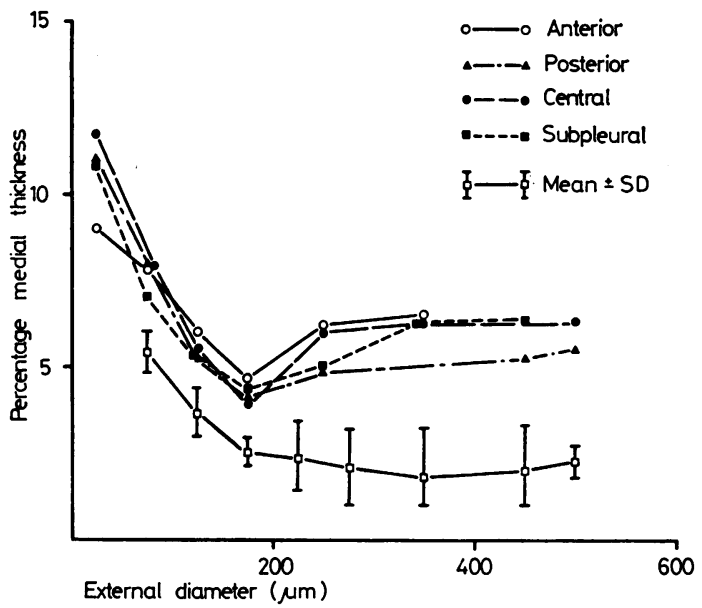

Fig. 1 Case 4 Arterial wall thickness (mean $\pm S D$ ) related to external diameter $(\mu \mathrm{m})$ in four sections from the left lower lobe, showing in all sections a similar increase in wall thickness above the normal range and extension of muscle into smaller arteries than normal.

Alveolar and arterial number: alveolar/arterial ratio Within one section arterial number per unit area varied considerably from, for example, 0 to 4 arteries per field in the anterior region of the left upper lobe in case 1 , but the mean value was always below normal. Alveolar number showed the greatest variation of all structural features analysed. The range was wide in relation to the mean value which was always within the normal limits, themselves wide. For example, in one section alveolar number varied between different fields by as many as 12 , a large variation in relation to the mean for the section of 25.5 . Since in each section mean arterial number was reduced and the mean alveolar number was normal the alveolar/arterial ratio was increased. In 25 out of 38 sections the ratio was greater than 20 (normal $=12$ ).

The structural variation within one section of lung tissue was no greater in one region of the lung or in one case than another. All sections were obviously abnormal. Despite the frequently wide range of values, the degree of abnormality for each of the structural features analysed could be determined by the deviation of the mean from the normal mean value.

(2) COMPARISON OF STRUCTURAL CHANGES WITHIN A LOBE

Arterial muscularity

In the four sites within each lobe percentage arterial wall thickness was compared in 108 pairs of samples

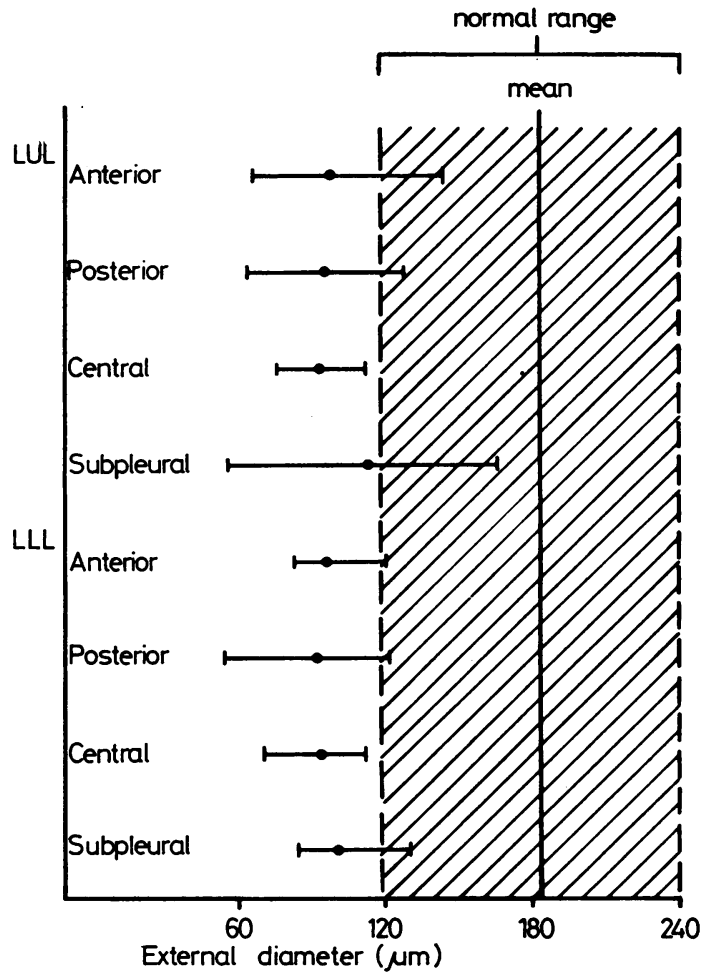

Fig. 2 Case 4 External diameter $(\mu m)$ of arteries accompanying respiratory bronchioli in each section of tissue from the left upper lobe (LUL) and left lower lobe ( $L L L)$, showing in all sections a similar reduction in size in comparison with the normal of the same age.

$\mathrm{I} \longrightarrow \mathrm{I}$ mean and range in each section.

of arteries separated into various size groups. An additional 130 pairs of samples contained too few measurements of wall thickness to allow a statistical comparison to be made. In 90 out of the 108 pairs of samples no statistical difference in percentage arterial medial thickness emerged (Fig. 1). In the other 18 pairs the significant difference usually occurred in arteries of 50 to $100 \mu \mathrm{m}$ in diameter, the size range containing the greatest number, but the difference was small in comparison to the increase above the normal level apparent in each of these sections. No consistent difference emerged between one region of a lobe and another, with the possible exception of the lingula where in the 2 cases examined (cases 1 and 4), arteries were thicker walled than those in the rest of the left lung. Only in case 1 did the difference reach statistical significance and then only in arteries less than 
$300 \mu \mathrm{m}$ in diameter $(\mathrm{P}<0.001$ in four size groups and $<0.01$ in the remaining group).

The distribution of muscle along the arterial pathway did not differ as between sections of the same lobe.

\section{Size of arteries accompanying respiratory bronchioli}

The mean external diameter of arteries accompanying respiratory bronchioli did not differ significantly in 21 out of 29 paired samples (Fig. 2). In the remaining 8 pairs the difference was small when related either to the mean value of external diameter or to the degree of reduction in size below normal. In case 1 , for example, the difference in mean external diameter between arteries accompanying the respiratory bronchioli in the anterior and posterior parts of the left upper lobe was $11.4 \mu \mathrm{m}$ $(\mathrm{P}<0.001)$. The mean arterial size of arteries in the anterior part was $103.3 \mu \mathrm{m}$ and in the posterior part $91.9 \mu \mathrm{m}$ (normal for each being more than $122 \mu \mathrm{m})$.

Arterial and alveolar number: alveolar/arterial ratio The mean arterial number per field did not differ significantly between sections taken from various parts of one lobe, whereas in 18 out of 29 paired samples from various regions of the same lobe the mean alveolar number per field differed significantly, but the difference was remarkably small, in 12 instances 3 alveoli or less. Thus, though alveolar number may vary considerably in different parts of the same section the mean value for a section is representative of the lobe.

The alveolar/arterial ratio varied only slightly in different parts of the same lobe, being 3 or less in 12 of 19 comparisons. In the remaining 7 comparisons, however, the difference varied from $3 \cdot 7$ to $12 \cdot 8$. This variation reflected relatively large variations in mean alveolar number and small variations in mean arterial number in different parts of the same lobe. The differences in arterial and alveolar number, and hence in the alveolar/ arterial ratio, were randomly distributed within the lobe and did not represent regional variation in lung structure.

\section{(3) COMPARISON OF STRUCTURAL CHANGES} WITHIN A LUNG

Arterial muscularity

The upper and lower lobes of the same lung showed no significant difference in mean percentage arterial thickness in 33 paired samples of arteries in different size grouls. From an additional 8 paired samples insufficient information was available to allow statistical comparison to be made, but neither lobe had arteries with consistently thicker walls than the other. No difference was found in the distribution of muscle along the arterial pathway.

Size of arteries accompanying respiratory bronchioli No significant difference in arterial size was demonstrated between the lobes.

Arterial and alveolar number: alveolar/arterial ratio Neither arterial nor alveolar number nor the alveolar/arterial ratio differed significantly in the upper and lower lobes.

(4) COMPARISON OF STRUCTURAL CHANGES IN RIGHT AND LEFT LUNG (CASES 1 AND 2) Arterial muscularity

The arteries of the right lung had a greater percentage arterial medial thickness than those of the left and, with the exception of three size groups in case 1 , the difference was significant though small when compared with the increase above the normal value. The distribution of muscle along the arterial pathway did not differ in the two lungs.

Size of arteries accompanying respiratory bronchioli Between the right and left lung, no consistent difference in arterial size emerged, the arteries of the right lung being smaller than those of the left in case 1 (mean difference $13.1 \mu \mathrm{m}$ ) and slightly larger $(7 \cdot 1 \mu \mathrm{m})$ in case 2 .

Arterial and alveolar number: alveolar/arterial ratio The mean arterial number per field differed significantly in the two lungs of case 1 , where there were more arteries in the left than the right lung, but in case 2 they were similar in both lungs. In case $1 \mathrm{a} P$ value of 0.001 arose from a difference in the mean value of only 0.32 arteries per field. Alveolar number differed significantly between the two lungs in both cases 1 and 2, a difference in the mean value of 1.89 and 2 alveoli per field respectively, giving a $\mathrm{P}$ value of $<0.001$. Because the direction of change for both arterial and alveolar number was different in the 2 cases, no importance can be attached to the difference demonstrated between the two lungs. Similarly in both cases the alveolar/arterial ratio was different in the 2 lungs, significantly so in case $2(P<0 \cdot 1)$, but the direction of change was different in the 2 cases.

The only structural difference between the 2 lungs was the greater wall thickness seen in the right lung vessels, and this difference was small compared with the deviation from normal. There was no consistent difference in arterial size or number or in alveolar number between both lungs. 


\section{Discussion}

In the sections from the 4 cases of ventricular septal defect with pulmonary hypertension a section of tissue taken from any part of either lung is representative of the whole. Each section, though only $1 \mathrm{~cm}^{2}$, sufficed for a satisfactory appraisal of the state of the lungs as to the degree both of hypoplasia of the pulmonary circulation and of excessive muscularisation of arteries, as judged both by wall thickness and extension of muscle abnormally far to the periphery. It may be desirable to avoid the lingula since it tends to have thicker arterial walls than the other regions.

Although the techniques of injection and inflation used to prepare the lung tissue were essential for this precise comparison between the various sections, certain assessments could have been made on uninjected material such as would be obtained at biopsy. It is desirable that inflated lung tissue be studied and this can be achieved at biopsy if the anaesthetist inflates the lung, the surgeon clamps the tissue, and after excising it drops tissue and clamp into fixative. Small arteries at the lung periphery can then be, distinguished by their central position in the acinus from small veins that are at the periphery. Arteries can be "landmarked' by the airways they accompany even if the arteries are not injected. If the lung is inflated the arteries are sufficiently distended to assess arterial wall thickness though the size range will be wider than in injected tissue.

In the present study the accuracy with which measurements were made on injected material showed the variation in arterial size, number, and muscularity occurring within one section of tissue. Even in the normal lung some variation in these features exists and for certain structural features variation may increase in disease. In these 4 cases of ventricular septal defect and pulmonary hypertension in vessels of all sizes the range of values of arterial wall thickness was greater than in the normal and this increased as vessel size diminished, probably because the appearance or hypertrophy of a single muscle cell in a non-muscular or partially muscular artery causes a greater change in relative wall thickness than does the concentric hypertrophy of smooth muscle cells in the larger muscularised vessels.

The size and wall structure of arteries accompanying respiratory bronchioli vary in the normal lung because there are at least three generations of respiratory bronchioli and considerable change in size and wall structure can occur in arteries running along this length of pathway (Hislop and Reid, 1974). The range of values could be reduced by landmarking the arteries more precisely according to the generation of respiratory bronchioli which they are accompanying. In fact, respiratory bronchioli seen arising from terminal bronchioli are few whereas they are frequently seen giving rise to alveolar ducts, and the possibility of assessing wall structure and size more precisely at distal respiratory bronchiolar level is being explored. In the presence of pulmonary hypertension, however, there was less variation in wall structure than in the normal lung since no non-muscular arteries were found accompanying respiratory bronchioli. The proportion of partially muscular and muscular arteries varied considerably, presumably because non-muscular arteries must first acquire a partially muscular coat and then, together with the arteries already containing smooth muscle cells, develop an entirely muscularised wall. The size of arteries accompanying the respiratory bronchioli also showed less variation than in normal children probably because in ventricular septal defect the arteries had failed to grow normally and remained within the narrower range normally found in younger children.

The techniques of injection and analysis used in this study have shown, therefore, that pulmonary hypertension produces a constant but variable reduction in lung growth and an increase in arterial muscularity. These structural variations in the early stages of pulmonary vascular disease are found throughout the lung and are apparent within a small volume of lung tissue.

The critical question is whether tissue obtained at lung biopsy contains sufficient and suitable material for analysis of the structural state of the lung. A section of lung periphery contains many small arteries less than $300 \mu \mathrm{m}$ in diameter and it is in these vessels that muscle cells first appear or hypertrophy when pulmonary hypertension occurs (Wagenvoort et al., 1964), or, in the experimental animal, on exposure to hypoxia (Hislop and Reid, 1976). In 41 out of 42 sections in the present study the mean arterial wall thickness was clearly above normal in all size groups and even in the odd section the wall thickness was increased in all but one size group and the increase in muscularity was obvious. In most sections 20 respiratory bronchioli could be identified, a sufficient number to assess accurately the size and wall structure of arteries at this level. The size and structure of arteries accompanying the alveolar ducts and lying within the alveolar wall could also be analysed. Accurate determination of alveolar and arterial counts depends on the alveoli throughout the specimen being distended to approximately the same size, which is achieved by taking the biopsy specimen from the inflated lung and fixing it while still inflated. 
If assessment of lung structure is to be as complete as in the present study then the techniques of measurement and analysis used here must beapplied. Quantitative analysis and detailed interpretation of biopsy material not only indicates changes in arterial wall structure, but can reveal how pulmonary hypertension affects the growth and development of the pulmonary circulation before obliterative pulmonary vascular change develops (Rabinovitch et al., 1977). Structural changes of growth and development of the lung are being correlated with functional change and their assessment is helping us to decide the most suitable time for surgical treatment as well as to predict the outcome. The uniformity of these changes through the lungs reported here is the justification for recommending biopsy.

We thank Professor B. Benjamin for his help with the statistical analysis of the data.

\section{References}

Davies, G., and Reid, L. (1970). Growth of the alveoli and pulmonary arteries in childhood. Thorax, 25, 669-681.

Harrison, C. V. (1958). The pathology of the pulmonary vessels in pulmonary hypertension. British fournal of Radiology, 31, 217-226.

Haworth, S. G., Sauer, U., Bühlmeyer, K., and Reid, L. (1977). The development of the pulmonary circulation in ventricular septal defect: a quantitative structural study. American fournal of Cardiology, 40, 781-788.

Heath, D., and Best, P. V. (1958). The tunica media of the arteries of the lung in pulmonary hypertension. Fournal of Pathology and Bacteriology, 76, 165-174.

Hislop, A. H. (1971). The fetal and childhood development of the pulmonary circulation and its disturbance in certain types of congenital heart disease. Ph.D. Thesis, University of London.

Hislop, A., and Reid, L. (1970). New pathological findings in emphysema of childhood: 1. Polyalveolar lobe with emphysema. Thorax, 25, 682-690.

Hislop, A., and Reid, L. (1973). Pulmonary arterial development during childhood-branching pattern and structure. Thorax, 28, 129-135.

Hislop, A., and Reid, L. (1974). Development of the acinus in the human lung. Thorax, 29, 90-94.

Hislop, A., and Reid, L. (1976). New findings in pulmonary arteries of rats with hypoxia induced pulmonary hypertension. British fournal of Experimental Pathology, 57, 542-554.

Hoffman, J. I. E. (1972). Diagnosis and treatment of pulmonary vascular disease. Birth Defects: Original Article Series, 8, No. 1, 9-18.

Rabinovitch, M., Haworth, S. G., Castenada, A., Nadas, A. S., and Reid, L. (1977). The lung biopsy in congenital heart disease. A morphometric approach to pulmonary vascular disease (abstract). Circulation, 56, Suppl. III, 193.

Reid, L. (1965). The angiogram and pulmonary artery structure and branching (in the normal and with reference to disease). Proceedings of the Royal Society of Medicine, 58, 681-684.

Simons, P., and Reid, L. (1969). Muscularity of pulmonary artery branches in the upper and lower lobes of the normal, young and aged lung. British fournal of Diseases of the Chest, 63, 38-44.

Wagenvoort, C. A. (1960). Vasoconstriction and medial hypertrophy in pulmonary hypertension. Circulation, 22, 535-546.

Wagenvoort, C. A., Heath, D., and Edwards, J. E. (1964). The Pathology of the Pulmonary Vasculature. Thomas, Springfield, Illinois.

Requests for reprints to Dr S. G. Haworth, Department of Paediatric Cardiology, The Hospital for Sick Children, Great Ormond Street, London WC1N 3JH. 